EGU2020-10110

https://doi.org/10.5194/egusphere-egu2020-10110

EGU General Assembly 2020

(c) Author(s) 2021. This work is distributed under

the Creative Commons Attribution 4.0 License.

\title{
Drilling the Tore seamount- Archive of a natural oceanic sediment trap
}

Susana M. Lebreiro ${ }^{1}$, Silvia Nave ${ }^{2}$, Laura Antón ${ }^{1}$, Elizabeth Michel $^{3}$, Catherine Kissel ${ }^{3}$, Claire Waelbroeck ${ }^{3}$, Nick McCave ${ }^{4}$, David Hodell ${ }^{4}$, Jose-Abel Flores ${ }^{5}$, Francisca Martinez-Ruiz ${ }^{6}$, Belén Martrat ${ }^{7}$, Cristina Roque ${ }^{8}$, Alex Piotrowski ${ }^{4}$, Luke Skinner ${ }^{4}$, Francisco Sierro ${ }^{5}$, Pedro Terrinha ${ }^{8}$, Guy Cornen ${ }^{9}$, María Isabel Reguera' ${ }^{1}$, Rocío Lozano-Luz ${ }^{1}$, and Natalia Bravo ${ }^{1}$

${ }^{1}$ Instituto Geológico y Minero de España, Madrid, Spain (susana.lebreiro@igme.es)

${ }^{2}$ Laboratorio Nacional Energia e Geologia, Alfragide, Portugal

${ }^{3}$ Laboratoire des Sciences du Climat et de l'Environnement, Gif-sur-Yvette, France

${ }^{4}$ Godwin Laboratory, University of Cambridge, Cambridge, United Kingdom

${ }^{5}$ University of Salamanca, Salamanca, Spain

${ }^{6}$ Instituto Andaluz de Ciencias de la Tierra-CSIC, Universidad de Granada, Granada, Spain

${ }^{7}$ Institute of Environmental Assessment and Water Research-CSIC, Barcelona, Spain

${ }^{8}$ Instituto Português do Mar e Atmosfera, Lisboa, Portugal

${ }^{9}$ University of Nantes, Nantes, France

Located $300 \mathrm{~km}$ off West Iberia in the open NE Atlantic Ocean, the Tore seamount emerges from the $5.5 \mathrm{~km}$ surrounding abyssal plains to a summit rim at $2.2 \mathrm{~km}$, which has an elliptical crater-like shape with a central depression $100 \mathrm{~km}$ in diameter. The $\sim 5.5 \mathrm{~km}$ depth of the Tore internal basin is connected to the surrounding deep ocean basin by a single narrow gateway down to $4.3 \mathrm{~km}$ depth. This basin is exceptional because it is 1) a giant sediment-trap for vertical fluxes, with sediments unaffected by deep currents and erosion, containing a record of enhanced biogenic subtropical productivity during deglaciations, which can be examined mechanistically, 2) a natural laboratory to examine carbonate dissolution at $5.5 \mathrm{~km}$ water depth constrained by NADW deep ventilation during glacials, and 3) an excellent location to test sediment processes distant from continental margins and understand triggering mechanisms of downslope flows in the open, deep ocean. Not many cores have been recovered in the area at such $5.5 \mathrm{~km}$ depth and unite this singular environment. At the larger scale of North Atlantic circulation and productivity, the semiisolated Tore seamount is a most valuable site to assess crucial scientific hypotheses related to thermohaline circulation, carbon cycling and climate variability. These challenging questions are framed in the IODP Initial Science Plan illuminating Earth's Past, Present and Future, 2013-2023, theme Climate and Ocean Change.

Our APL applies for drilling one site in the middle of the Tore seamount at $5.5 \mathrm{~km}$ depth, to retrieve a complete Quaternary sedimentary sequence (180 m long). This carbonate rich archive will be compared with records available in the Northeast Atlantic and to be recovered during Expedition \#771-Full2 (Hodell et al.). 
We present results from a 24 long giant Calypso core taken in the APL-site proposed which covers 430 thousand years and 5 glacial-interglacial cycles (Spanish project "TORE5deglaciations", CTM2017-84113-R, 2018-2020). 